\title{
Tryptophan Regulates Thaxtomin A and Indole-3-Acetic Acid Production in Streptomyces scabiei and Modifies Its Interactions with Radish Seedlings
}

\author{
Geneviève S. Legault, Sylvain Lerat, Philippe Nicolas, and Carole Beaulieu
}

Centre SÈVE, Département de biologie, Université de Sherbrooke, Sherbrooke, Québec J1K 2R1, Canada.

Accepted for publication 19 April 2011.

\begin{abstract}
Legault, G. S., Lerat, S., Nicolas, P., and Beaulieu, C. 2011. Tryptophan regulates thaxtomin A and indole-3-acetic acid production in Streptomyces scabiei and modifies its interactions with radish seedlings. Phytopathology 101:1045-1051.

The virulence of Streptomyces scabiei, the causal agent of common scab, depends mainly on the production of the toxin thaxtomin A. S. scabiei also produces indole-3-acetic acid (IAA) but the role of this hormone in the interaction between pathogenic streptomycetes and plants has not yet been elucidated. Tryptophan is a biosynthetic precursor of both IAA and thaxtomin A. In this study, the effect of tryptophan on

of the corresponding biosynthetic genes in S. scabiei has been analyzed. In vitro IAA production depended on the availability of tryptophan. However, addition of this amino acid to the culture medium inhibited the biosynthesis of thaxtomin A. Expression of thaxtomin A biosynthetic genes nos and $t x t A$ were strongly repressed in the presence of tryptophan; however, modulation of the expression was not observed for the IAA biosynthetic genes $i a a M$ and $i a a H$. The effects of an exogenous tryptophan supply on $S$. scabiei virulence were assessed on radish seedlings. Addition of tryptophan reduced symptoms on inoculated radish roots compared with seedlings grown in the absence of the bacterium, by way of inhibition of thaxtomin A production and increase of IAA biosynthesis.
\end{abstract} thaxtomin A and IAA production as well as its effect on the transcription
Bacteria of the genus Streptomyces are gram-positive, soilfilamentous microorganisms with a saprophytic life cycle. However, a few species are recognized as plant-pathogenic agents and are responsible for common scab, a worldwide disease that affects most tap root and tuber crops $(11,31)$. Streptomyces scabiei (syn. S. scabies) is the main causal agent of common scab of potato. Symptoms consist of shallow, raised, or deep-pitted lesions that substantially reduce crop value $(15,34)$. Moreover, in addition to the symptoms observed on diverse root crops, S. scabiei also inhibits the growth of various monocot and dicot seedlings (29).

Virulence of the common scab-causing Streptomyces spp. relies on the production of cyclized dipeptides known as thaxtomins $(23,25,26)$. These toxins are considered to be the most important virulence factors $(12,25,36)$. The mechanism of action of thaxtomins is not fully understood; however, thaxtomins have been shown to inhibit synthesis of the plant cell wall component cellulose (10). Thaxtomin A is the prevalent form of toxin produced by S. scabiei (24). Biosynthesis of this phytotoxic compound is nonribosomal and is achieved by the cyclization of nitrated tryptophan and phenylalanine by a peptide synthetase (TxtAB) (14). Nitration of the tryptophan residue, catalyzed by a nitric oxide synthase (Nos), is essential to the toxicity of thaxtomins (22).

In liquid culture media, biosynthesis of thaxtomin $\mathrm{A}$ has been shown to be induced by certain plant-derived compounds. For example, oat bran broth is an excellent medium for routine production of thaxtomin $A(5,12)$. In a recent study, the presence of D-(+)-cellobiose and suberin were shown to induce thaxtomin A production in S. scabiei strain EF-35 (32). However, other compounds may inhibit thaxtomin A production. For example, the

Corresponding author: C. Beaulieu;

E-mail address: Carole.Beaulieu@usherbrooke.ca

doi:10.1094/PHYTO-03-11-0064

(c) 2011 The American Phytopathological Society phytoalexin scopoletin (30) and $0.5 \%$ glucose $(2,36)$ inhibited thaxtomin A synthesis. More surprisingly, the presence of the biosynthetic precursors of the toxin, tryptophan and phenylalanine, also caused a drastic reduction of thaxtomin A production in oat bran medium (27).

Streptomyces spp. are also known to produce a wide range of metabolites, including tryptophan-derived molecules. Among these is the phytohormone auxin (indole-3-acetic acid [IAA]) $(6,45)$. The biosynthetic pathway of IAA has been elucidated in streptomycetes (37). Moreover, the genome of S. scabiei contains two adjacent open reading frames (ORFs) sharing 93\% identity with gene iaaM of $S$. coelicolor and $85 \%$ identity with gene $i a a H$ of $S$. avermitilis. The involvement of these genes in IAA biosynthesis by $S$. scabiei has recently been demonstrated by gene disruption experiments (16). In most soilborne bacteria, IAA synthesis was shown to be tryptophan dependent $(18,41)$. However, stimulation of IAA production by the exogenous addition of tryptophan has not previously been demonstrated in S. scabiei.

Previous studies have reported on the beneficial role of foliar application of IAA and other auxin-like compounds against common scab symptoms under controlled conditions $(38,39,46)$. The beneficial effect of IAA and auxin-like molecules was proposed to be caused by competition between auxin and thaxtomin for a putative cellular binding site. Moreover, accumulation of auxin-like compounds in tubers of treated plants was associated with enhanced tolerance to thaxtomin A (46). However, the interaction between auxin and thaxtomin has yet to be clarified.

This report investigates the influence of tryptophan on thaxtomin A and IAA production and on the transcription of the corresponding biosynthetic genes in $S$. scabiei. Because the amount of thaxtomin A synthesized by $S$. scabiei positively correlates with the severity of symptoms developed on the host plant $(25$, 36 ), the effect of exogenous supply of tryptophan on S. scabiei virulence was examined on radish seedlings grown under gnotobiotic conditions. 


\section{MATERIALS AND METHODS}

Preparation of bacterial inoculum. S. scabiei strain EF-35 (8) was cultivated in tryptic soy broth at $30^{\circ} \mathrm{C}$ in a rotary shaker $(250 \mathrm{rpm})$ for $48 \mathrm{~h}$. Cultures were then centrifuged $(5 \mathrm{~min}, 4,000 \times$ $g$ ) and cell pellets were washed with sterile saline $(0.85 \% \mathrm{NaCl})$ and resuspended in 5 volumes of fresh saline. These bacterial suspensions were subsequently used for inoculation.

Thaxtomin A and IAA quantification in liquid media. The effect of tryptophan on thaxtomin A and IAA biosynthesis by $S$. scabiei EF-35 was assessed in minimal medium supplemented with cellobiose and suberin (SCM) (32). This medium is recognized for inducing thaxtomin A production by $S$. scabiei EF-35 (32). Bacterial inoculum $(100 \mu \mathrm{l})$ was added to $25 \mathrm{ml}$ of SCM supplemented with different L-tryptophan concentrations (0 to $10.0 \mathrm{mM}$ ) (Sigma-Aldrich, St. Louis) and the cultures were incubated for 6 days at $30^{\circ} \mathrm{C}$ with agitation $(250 \mathrm{rpm})$. Experiments were carried out once in triplicate.

The 6-day-old SCM cultures were centrifuged for $5 \min (4,000 \times$ $g$ ). Cell pellets were dried and weighed to quantify bacterial growth. Thaxtomin A and IAA were extracted from supernatants with ethyl acetate according to Beauséjour et al. (5), with the following modifications: experiments were conducted in the dark to avoid IAA degradation and supernatant $\mathrm{pH}$ was adjusted to 2.0 with $5.0 \mathrm{~N} \mathrm{HCl}$ to ensure efficient extraction of IAA with ethyl acetate (this did not alter thaxtomin A extraction yields; unpublished results).

Thaxtomin A was then quantified with reverse-phase high-performance liquid chromatography (HPLC) using a Varian ProStar 215 system and a 150-by-4.6-mm Polaris C18-A 5- $\mu$ m column. Thaxtomin A elution was carried out with a 25 to $75 \%$ acetonitrile linear gradient and detected at $249 \mathrm{~nm}$ with a Varian ProStar 325 UV-Vis detector. IAA was quantified at $280 \mathrm{~nm}$ using a 10 to $90 \%$ acetonitrile (in $0.1 \%$ acetic acid) linear gradient (modified from Vega-Hernández et al. [47]).

Gene expression studies. The expression of genes involved in thaxtomin A and IAA biosynthesis was examined. Genes involved in thaxtomin A synthesis included txtA and nos (32) whereas, for IAA synthesis, two adjacent ORFs sharing 93\% identity with gene iaaM of $S$. coelicolor and $85 \%$ identity with gene iaaH of $S$. avermitilis were targeted. Samples $(5 \mathrm{ml})$ were taken from SCM cultures after $48 \mathrm{~h}$. Stop solution (0.2 volumes of $5 \%$ acidic phenol in ethanol) was added to the samples to prevent RNA degradation. Bacterial cells were recovered by centrifugation $(4,000 \times g, 5 \mathrm{~min})$ and stored at $-80^{\circ} \mathrm{C}$ until RNA extraction.

Extraction of total RNA was performed with the RNeasy Minikit (Qiagen, Mississauga, ON, Canada) following the manufacturer's instructions, with addition of a sonication step $(2 \times 30 \mathrm{~s}$ on ice) to improve lysis, followed by a phenol/chloroform extraction step. DNA digestion following manufacturers' instructions was performed both on column (RNase-Free DNase; Qiagen) and after RNA elution (Turbo DNase; Ambion, Austin, TX). cDNA was generated performing reverse transcription on $4 \mu \mathrm{g}$ of total RNA with the First-Strand cDNA Synthesis kit (GE Healthcare, Baie d'Urfé, QC, Canada) using 72\% G+C-rich random hexamers (Sigma Genosys, The Woodlands, TX).
Quantitative real-time reverse-transcription polymerase chain reaction (RT-PCR) analysis of gene transcripts was conducted on the Stratagene Mx3000P with SYBR Green PCR master mix and JumpStart Taq DNA Polymerase (Sigma-Aldrich). PCR conditions were $95^{\circ} \mathrm{C}$ for $5 \mathrm{~min}$ followed by 35 cycles at $95^{\circ} \mathrm{C}$ for $15 \mathrm{~s}$ and $60^{\circ} \mathrm{C}$ for $45 \mathrm{~s}$. Primers used to amplify thaxtomin A and IAA biosynthetic genes and the reference gene gyrase A ( gyrA) are listed in Table 1. gyrA is commonly used as reference gene in the genus Streptomyces $(21,30,32)$ and transcription rates of gyrA were shown to be uniform among conditions tested in this study (data not shown). Relative quantification of transcripts was determined using the Pfaffl equation (43).

Pathogenicity assays on radish seedlings. A gnotobiotic hydroponic system with radish seedlings was used to evaluate the effect of tryptophan on S. scabiei virulence. Radish (Raphanus sativus 'Cherry Belle') seedlings were obtained by soaking seeds, first in a $70 \%$ ethanol solution for $5 \mathrm{~min}$ and then twice in a wash solution $(10 \%$ commercial bleach with $0.02 \%$ sodium dodecyl sulfate) for $5 \mathrm{~min}$. Seeds were subsequently rinsed three times with distilled sterile water. Seeds were then placed on $1.5 \%$ agar plates for $48 \mathrm{~h}$ in the dark at $30^{\circ} \mathrm{C}$. Six germinated seeds were placed in autoclaved growth pouches $(18.0 \times 16.5 \mathrm{~cm}$, CYG seed germination pouch; Mega International, West St. Paul, MN). Pouches were covered with aluminum foil to prevent IAA degradation. Tryptophan solution $(20 \mathrm{ml}$ of $0,2.5,5.0$, or $7.5 \mathrm{mM}$ ) was added to each pouch. Individual pouches were then inoculated, or not, with $200 \mu \mathrm{l}$ of $S$. scabiei inoculum. An experimental unit consisted of six seedlings per pouch. Each treatment was carried out in four replicates and the experiment was repeated twice.

Pouches were placed in a growth chamber $\left(21^{\circ} \mathrm{C}, 18\right.$-h photoperiod, $65 \%$ relative humidity) for 6 days. Pouches were then digitally scanned using an EPSON Expression $836 \mathrm{XL}$ and analyzed with the WinRhizo software (V. 2002c; Pro Regent Instruments Inc., Québec, QC, Canada) to determine total root surface area. Bacterial effect represented the ratio between the root surface of radish seedlings inoculated with S. scabiei and root surface of noninoculated seedlings grown in the presence of the same tryptophan concentration.

Metabolite quantification and gene expression studies of $S$. scabiei in growth pouches. Quantification of thaxtomin A and IAA synthesized by $S$. scabiei in the presence of tryptophan and host plants was also performed in growth pouches as described above. In these assays, growth pouches contained $20 \mathrm{ml}$ of water or a solution of $7.5 \mathrm{mM}$ tryptophan, with or without $200 \mu \mathrm{l}$ of $S$. scabiei inoculum. After 6 days, the liquid remaining in the pouches was collected for thaxtomin A and IAA extraction and quantification, following the method described above.

In another experiment, the same system was used to assess tryptophan consumption by $S$. scabiei in growth pouches. Radish seedlings (five pouches of six seedlings per treatment) were inoculated with S. scabiei EF-35 or not inoculated (see above) and grown in the presence of $7.5 \mathrm{mM}$ tryptophan. After 6 days of growth, tryptophan was extracted from growth pouches, separated by HPLC (Varian ProStar 215 equipped with a 150-by-4.6-mm Polaris C18-A 5- $\mu$ m column), eluted with a 25 to $75 \%$ acetonitrile linear gradient, and quantified at $219 \mathrm{~nm}$ using a Varian ProStar $325 \mathrm{UV}-\mathrm{Vis}$ detector.

TABLE 1. Genes investigated in this study

\begin{tabular}{lllll}
\hline Function & Gene & Position $(\mathrm{ORF}, \mathrm{bp})^{\mathrm{a}}$ & Forward primer $\left(5^{\prime}-3^{\prime}\right)$ & Reverse primer $\left(5^{\prime}-3^{\prime}\right)$ \\
\hline Reference gene (21) & gyrA & $2,745,587(2,457)$ & ggacatccagacgcagtaca & ctcggtgttgagcttctcct \\
Thaxtomin A synthesis (32) & txtA & $3,604,857(4,377)$ & tcgccgcctacgtcatacccgagaa & cgtacagatcgtcgtagagccgtc \\
& nos & $3,615,200(1,173)$ & gagctggtcttggaggtccctatc & cgcatgttggagatgacgggtacg \\
IAA synthesis & iaaH & $8,348,535(789)$ & agatgcatccgttccagttcgt & acgtaggcgacgtacatctggttct \\
& iaaM & $8,349,372(1,698)$ & gatgacctcaccgaccgtatgac & ccaggtgtaggagaggcagatgac \\
\hline
\end{tabular}

\footnotetext{
${ }^{a}$ Start position on Streptomyces scabiei genome released by Sanger Institute (http://www.sanger.ac.uk/Projects/S_scabies/). ORF = open reading frame.
}

b IAA = indole-3-acetic acid. 
Growth pouches were again used to carry out expression studies of the thaxtomin A and IAA biosynthetic genes on bacteria interacting with radish seedlings. Liquid was collected from pouches 48 and $72 \mathrm{~h}$ after seedling inoculation, and stop solution was then added immediately. After centrifugation, bacterial pellets were kept at $-80^{\circ} \mathrm{C}$ prior to RNA extraction. Quantitative real-time RT-PCR was performed on thaxtomin A and IAA biosynthesis genes as described above. This experiment was repeated three times in duplicate.

Statistical analyses. Analyses of variance for all data were performed using SAS (V. 9.1; SAS Institute, Cary, NC). One- or two-way analyses of variance followed by least significant difference tests were carried out to analyze most experiments. Analysis of gene expression study in growth pouches was performed by $t$ test for each sampling time (48 and $72 \mathrm{~h}$ ). The accepted level of statistical significance was $P<0.05$.

\section{RESULTS}

Thaxtomin A and IAA biosynthesis are influenced by the presence of tryptophan. Thaxtomin A production by S. scabiei EF-35 was assessed in SCM, a medium that promotes thaxtomin A production (32). In the absence of tryptophan, thaxtomin A production yielded $4.69 \pm 0.34 \mathrm{mg} / \mathrm{g}$ bacterial dry weight (bact. DW) in SCM (Fig. 1A). However, the presence of different concentrations of the amino acid in SCM strongly inhibited toxin production. At the highest concentration tested (10.0 mM tryptophan), thaxtomin A at only $0.63 \pm 0.37 \mathrm{mg} / \mathrm{g}$ bact. DW was measured in SCM (Fig. 1A). Thus, the inhibition of thaxtomin A biosynthesis showed a negative correlation with tryptophan concentration $\left(r^{2}=0.645, P=0.0001\right)$.

Conversely, IAA production was strongly and significantly promoted by the exogenous addition of tryptophan (Fig. 1A). Without tryptophan, IAA production was $18.1 \pm 2.8 \mu \mathrm{g} / \mathrm{g}$ bact. DW in SCM (Fig. 1A). IAA production was 61-fold higher in the presence of $10.0 \mathrm{mM}$ tryptophan compared with nonsupplemented media. IAA production was strongly correlated with tryptophan concentrations in a linear manner $\left(r^{2}=0.965, P<0.0001\right)$. Tryptophan concentration did not significantly influence bacterial growth (Fig. 1B).

Tryptophan inhibits transcription of thaxtomin A biosynthesis genes. Two genes involved in thaxtomin A biosynthesis (txtA and nos) were monitored. The txtA and nos genes were significantly downregulated $(P<0.001)$ by increasing concentrations of tryptophan (Fig. 2A). In the presence of $7.5 \mathrm{mM}$ tryptophan, the txtA and nos genes were downregulated 12- and 25-fold, respectively (Fig. 2A).

Quantitative RT-PCR analysis of cDNA from S. scabiei cultivated in SCM supplemented with tryptophan revealed that there was no significant difference in the expression levels of the two genes involved in IAA biosynthesis, iaaM and iaaH, compared with the nonsupplemented treatment $(P=0.9030$ and 0.5015 , respectively) (Fig. 2B).

Tryptophan reduces severity of symptoms caused by $S$. scabiei on radish seedlings. In the absence of tryptophan, inoculation by $S$. scabiei caused a decrease of $65 \%$ of root surface compared with noninoculated radish seedlings (Fig. 3). Symptoms caused by S. scabiei appeared as brownish roots, shortening of the primary root, and inhibition of the emergence of lateral roots.

Addition of tryptophan in the noninoculated growth control pouches caused several changes in the root system. Radish seedlings were sensitive to high concentrations of this amino acid, which caused a reduction of total root length by $\approx 50 \%$ (data not shown). To evaluate the effect of different concentrations of tryptophan on symptoms caused by $S$. scabiei on radish seedlings, the ratio between total root surface of inoculated seedlings at a given tryptophan concentration and total root surface of non- inoculated radish at the same concentration was determined, which is hereafter referred to as the bacterial effect. Tryptophan had a significant impact on the bacterial effect of $S$. scabiei on total root surface of radish seedlings $(P<0.0001)$. Although the presence of the bacterium still reduced radish root surface at a tryptophan concentration of $2.5 \mathrm{mM}$, this negative effect nearly disappeared when the amino acid concentration reached $5.0 \mathrm{mM}$. Moreover, S. scabiei showed a positive effect on radish root surface at $7.5 \mathrm{mM}$ tryptophan (Fig. 3).

Thaxtomin A production in planta is inhibited in the presence of tryptophan. Quantification of thaxtomin A and IAA was performed in growth pouches on radish seedlings inoculated, or not, with S. scabiei, and in the presence or absence of tryptophan. As observed in liquid media, tryptophan affected thaxtomin A production (Fig. 4A). In the inoculated control pouches, total thaxtomin A reached $8.0 \pm 2.0 \mu \mathrm{g}$ per pouch, whereas the presence of tryptophan reduced thaxtomin A production by $63 \%(P=$ $0.0005)$. There was no significant consumption of tryptophan by $S$. scabiei because, after 6 days of incubation, tryptophan concentration was nearly identical $(P=0.8886)$ in inoculated $(7.63 \pm$ $0.34 \mathrm{mM})$ and noninoculated $(7.60 \pm 0.21 \mathrm{mM})$ growth pouches.

Analysis of the expression of the thaxtomin A biosynthetic genes in $S$. scabiei was performed in growth pouches. Their transcription levels differed between growth medium (Fig. 5A). Relative expressions of txtA and nos were significantly lower at $7.5 \mathrm{mM}$ tryptophan than in control pouches at both $48 \mathrm{~h}$

A

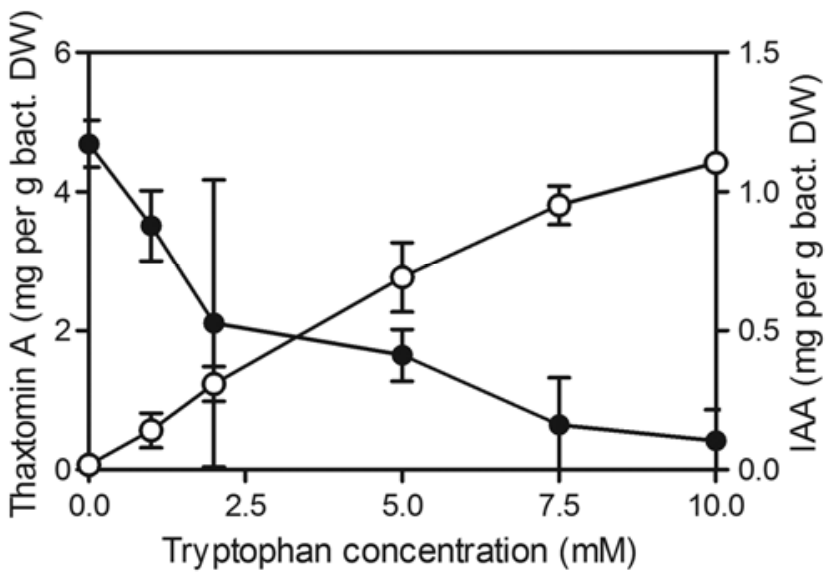

B

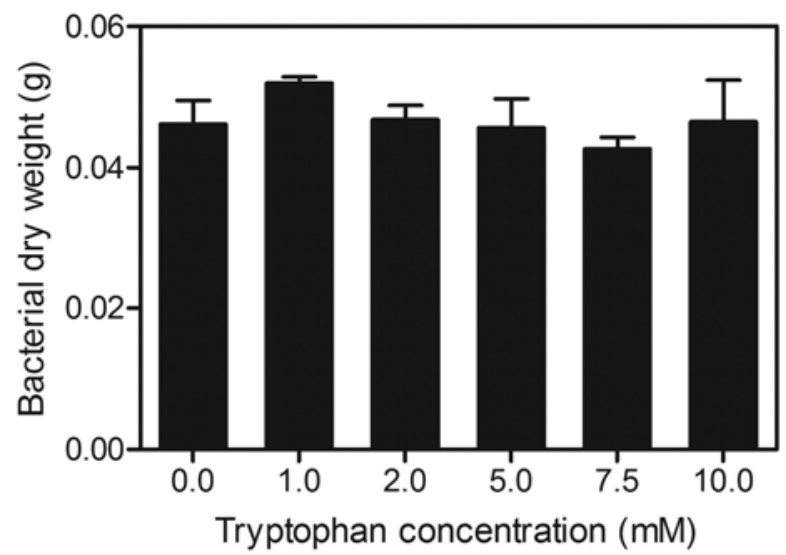

Fig. 1. A, Thaxtomin A (closed circles) and indole-3-acetic acid (open circles) production ( \pm standard deviation $[\mathrm{SD}]$ ) by Streptomyces scabiei EF-35 per bacterial dry weight (bact. DW) and $\mathbf{B}$, bacterial biomass $(+\mathrm{SD})$ as a function of tryptophan concentration, after 6 days of growth in thaxtomin-inducing minimal medium supplemented with cellobiose and suberin. The experiment was repeated once in triplicate. 
$(P=0.0159$ and 0.0016 , respectively $)$ and $72 \mathrm{~h}(P=0.0364$ and 0.0003 , respectively). Differences in IAA production were also observed between growth conditions (Fig. 4B). Low IAA levels were observed in the absence of inoculum. The presence of S. scabiei EF-35 significantly increased the amount of IAA in growth pouches in the absence of tryptophan, while the combination of bacterial inoculum and tryptophan boosted IAA production (Fig. 4B). However, as observed in liquid media, the presence of tryptophan in growth pouches had no significant impact on IAA biosynthetic genes $(P>0.10$ in all assays) (Fig. 5B).

\section{DISCUSSION}

In the present study, the production of the toxin thaxtomin A by the pathogenic agent $S$. scabiei was strongly inhibited by the presence of exogenous tryptophan in a liquid thaxtomin-inducing growth medium. Such inhibition of toxin production is in accordance with other reports $(2,27)$. Previous studies were carried out in rich media such as oat bran broth that intrinsically contains amino acids. In this study, tryptophan was added to SCM (32) (i.e., a growth medium that contains no aromatic amino acids).

The inhibition of thaxtomin A production caused by tryptophan appeared to occur, at least in part, at the level of gene regulation. The presence of tryptophan caused a downregulation of the expression of $t x t A$ and nos, two key genes coding for thaxtomin A biosynthetic enzymes. $t x t A$ encodes a peptide synthetase implicated in cyclization (14), while nos encodes a nitric oxide synthase involved in tryptophanyl nitration (22). The inhibition of the production of a metabolite by the addition of one of its biosynthetic precursors is uncommon (2). Many studies on different Streptomyces spp., such as $S$. avermitilis, S. clavuligerus, or $S$. antibioticus, have demonstrated an increased production of a metabolite with the exogenous addition of biosynthetic precursors $(44,48,50)$.

Conversely, biosynthesis of bacterial IAA has been extensively studied, and different pathways have been identified with strong similarities to plant biosynthetic pathways $(6,45,49)$. In most organisms, including S. scabiei, tryptophan is the precursor of IAA $(4,41)$. Several authors have reported a large increase in IAA biosynthesis in bacteria supplied with exogenous tryptophan. For instance, a fivefold stimulation of IAA production was observed

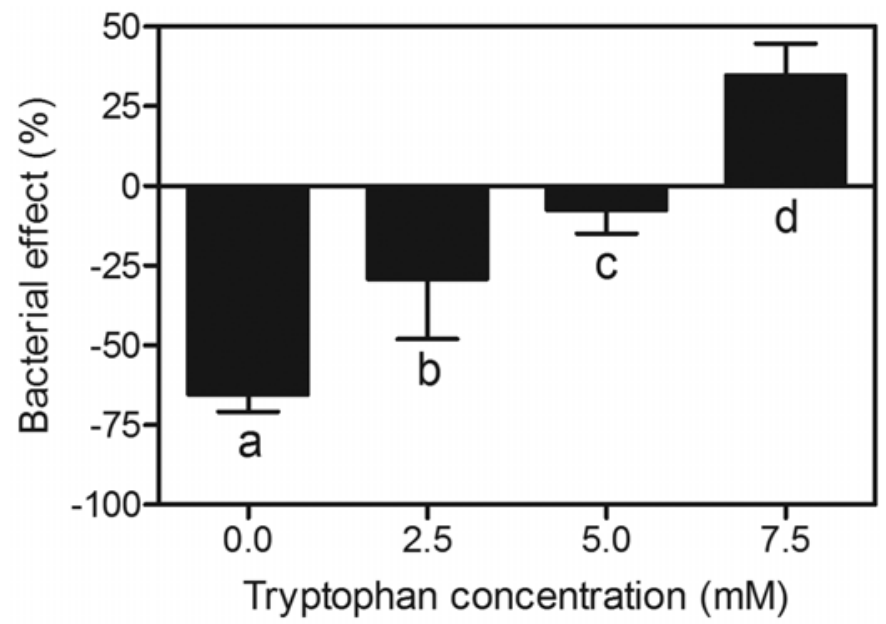

Fig. 3. Ratio between radish root surface of inoculated (Streptomyces scabiei EF-35) and noninoculated (control) pouches as a function of tryptophan concentration, 6 days after inoculation. Values are the mean ( \pm standard deviation) of two repetitions carried out with four replicates. Bars with the same letter are not significantly different (least significant difference test).
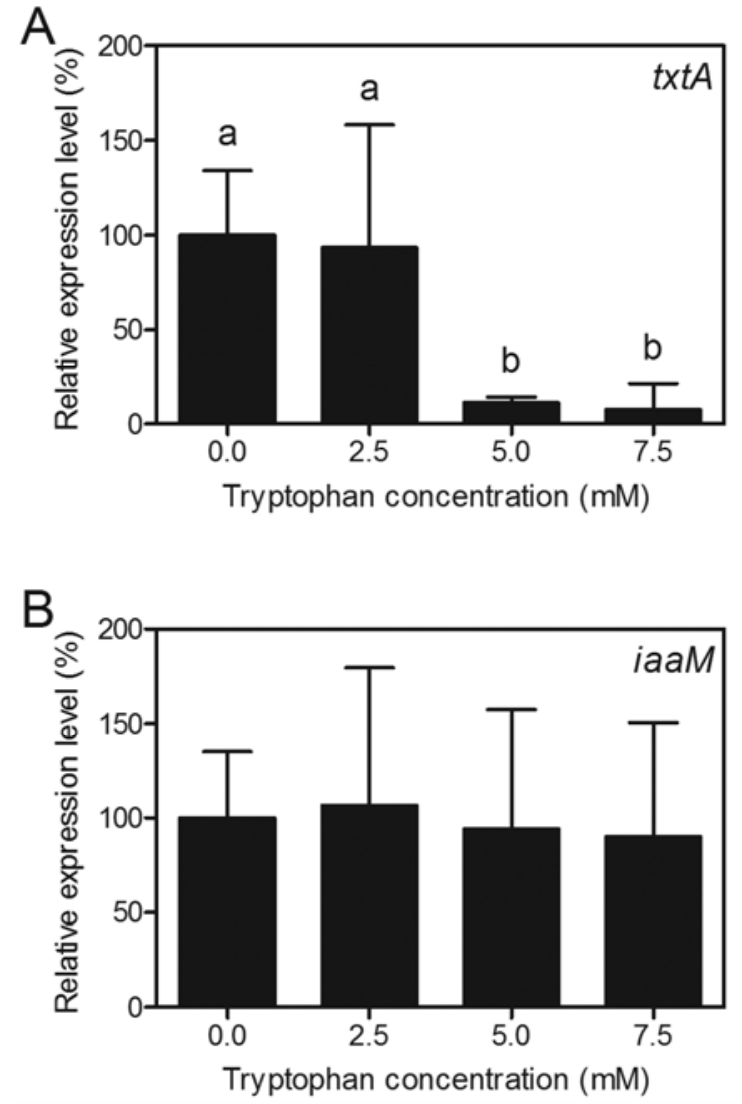
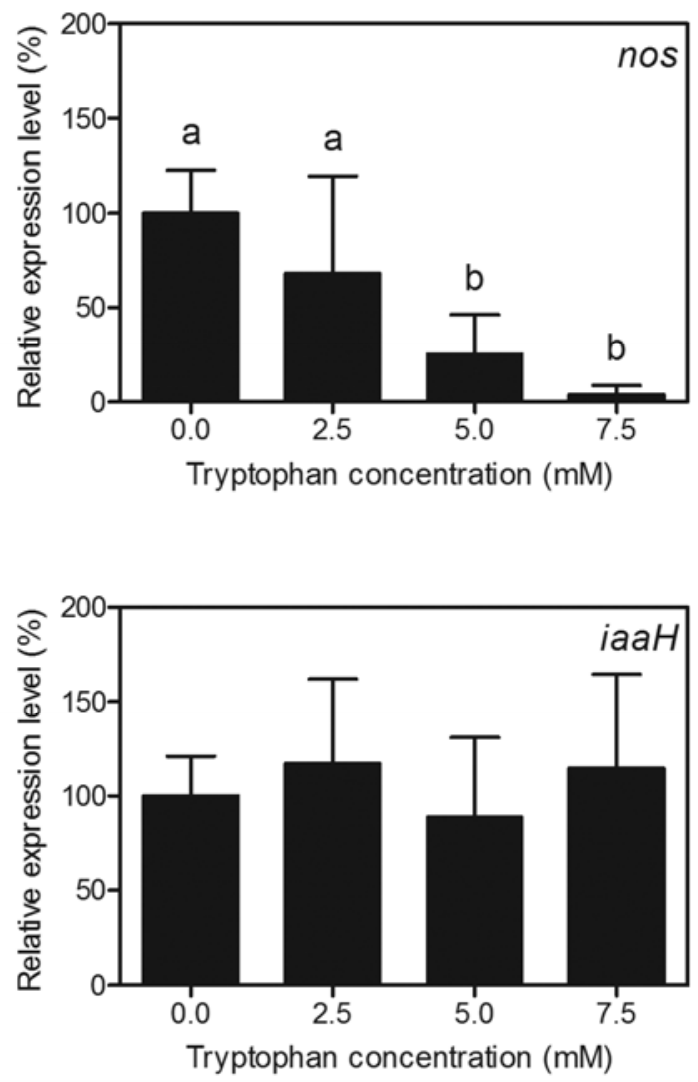

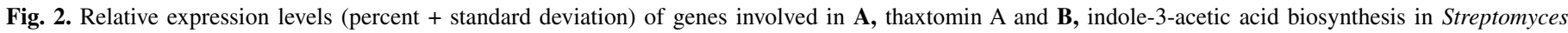

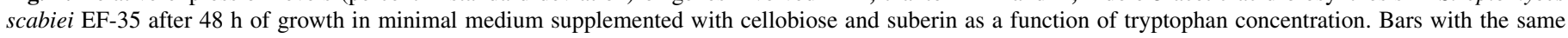
letter are not significantly different (least significant difference test). The experiment was repeated three times in triplicate. 


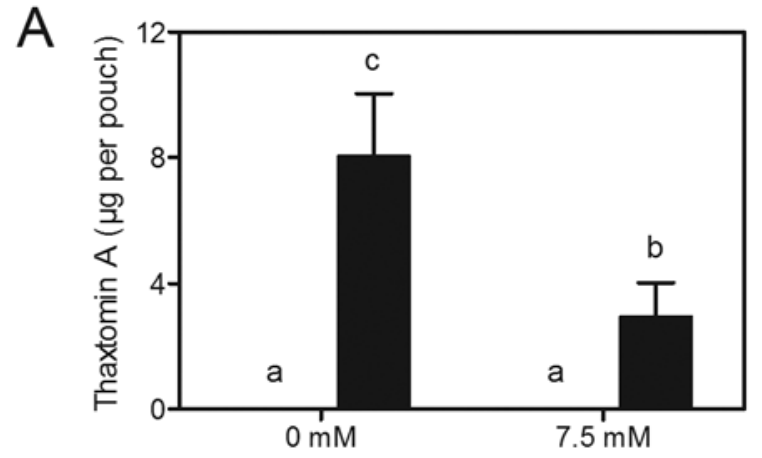

Tryptophan concentration

\section{B}

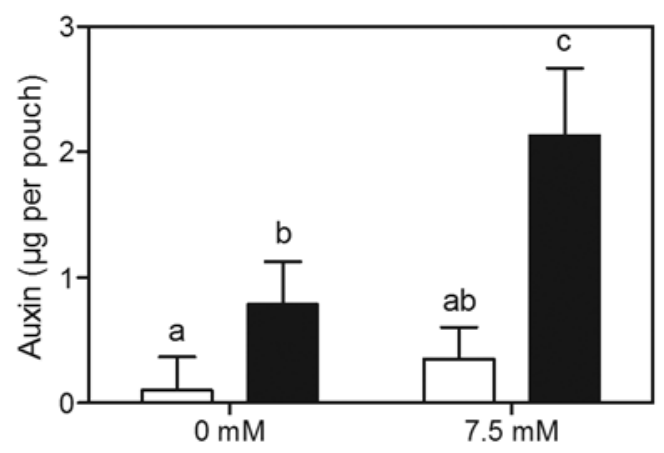

Tryptophan concentration

Fig. 4. A, Thaxtomin A and B, indole-3-acetic acid production in growth pouches containing 0 or $7.5 \mathrm{mM}$ tryptophan. Radish seedlings were bacteria free (white bars) or inoculated with Streptomyces scabiei EF-35 (black bars). Values are the mean (+ standard deviation) of one experiment carried out with seven replicates. Bars with the same letter are not significantly different (least significant difference test). in Bacillus amyloliquefaciens when $5.0 \mathrm{mM}$ tryptophan was added to the growth medium (18). In the plant growth-promoting rhizobacteria Pseudomonas putida, the addition of $2.4 \mathrm{mM}$ tryptophan to minimal liquid media stimulated IAA production by 60 -fold (42). In the present study, IAA production by S. scabiei was strongly increased in tryptophan-supplemented media. To assess whether tryptophan regulated IAA biosynthetic genes, quantification of two genes involved in the synthesis of this phytohormone was performed. Sequences exhibiting high homology to the coding sequences of the $S$. coelicolor tryptophan mono-oxygenase (iaaM) and the $S$. avermitilis indole-3-acetamide hydrolase $(i a a H)$ were identified in $S$. scabiei. The involvement of these genes in IAA synthesis in S. scabiei was recently confirmed by gene disruption (16). Neither of the IAA biosynthetic genes iaaM or iaaH showed tryptophan-induced transcriptional modulation. This is in accordance with previous studies, in which genes of the IAM pathway were reported to be constitutively expressed $(17,40)$. The strong linear correlation between tryptophan concentration and the production of bacterial IAA in SCM indicated that IaaM and IaaH are substrate-dependent enzymes.

Growth of radish seedlings is known to be altered by the presence of pathogenic S. scabiei strains, and radish seedlings have been commonly used in different assays for determining $S$. scabiei pathogenicity $(12,29)$. In the hydroponic system used here, radish root growth was inhibited in pouches inoculated with $S$. scabiei EF-35 (in the absence of tryptophan), indicating that root exudate components or radish root constituents provided sufficient thaxtomin A inducers to allow production of the toxin by the pathogen.

Because tryptophan induced a reduction in thaxtomin A production in $S$. scabiei grown in liquid media, the effect of this amino acid on bacterial virulence was also tested in the presence of radish seedlings. Increasing tryptophan concentrations induced a proportional reduction of symptoms on radish roots inoculated with S. scabiei compared with their noninoculated counterparts.
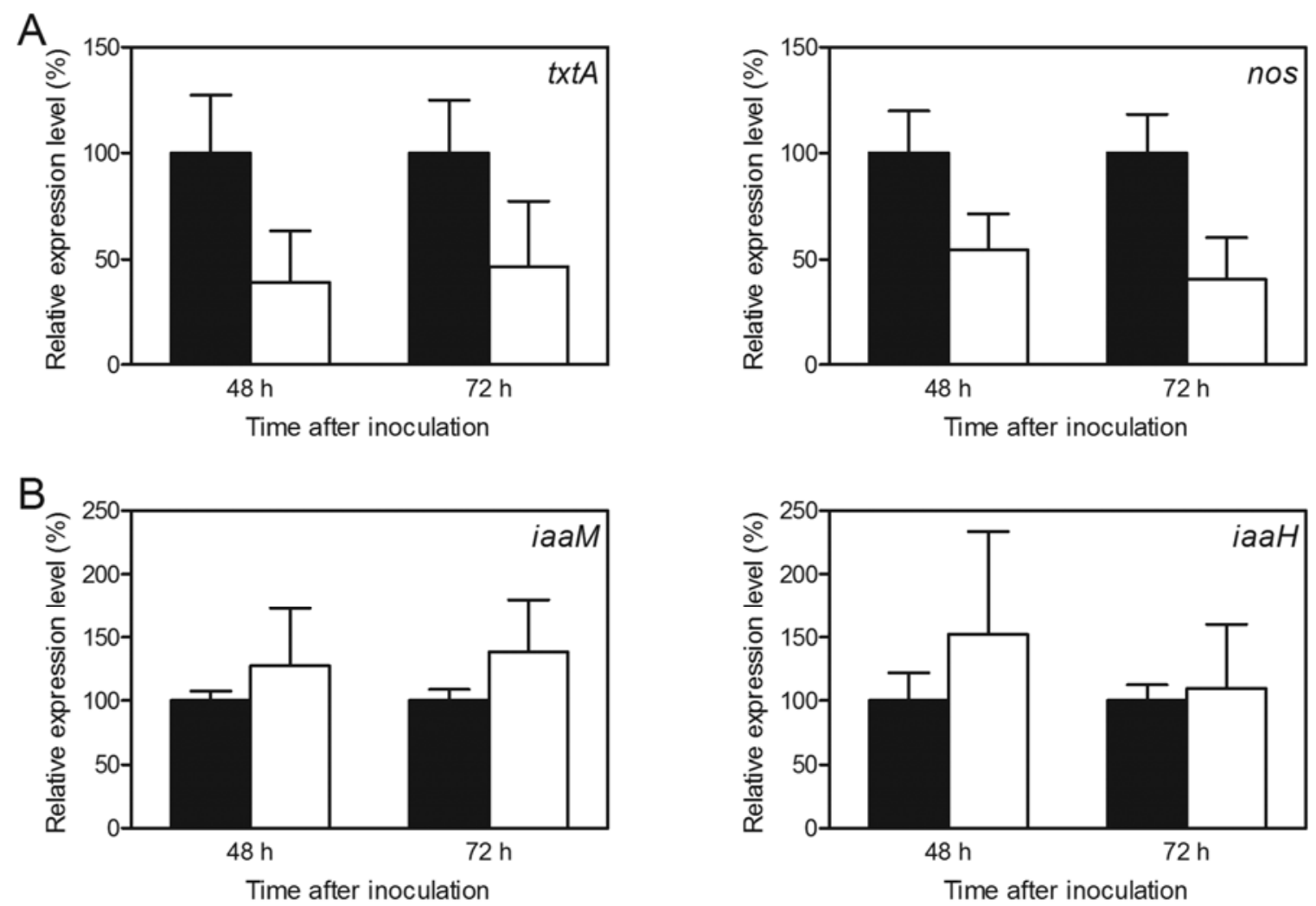

Fig. 5. Relative expression levels (percent + standard deviation) of genes involved in A, thaxtomin A and B, indole-3-acetic acid biosynthesis in Streptomyces scabiei EF-35 growth pouches at $0 \mathrm{mM}$ (black bars) and $7.5 \mathrm{mM}$ (white bars) tryptophan. Bacteria were sampled 48 and $72 \mathrm{~h}$ after inoculation of radish seedlings. Values are the mean of three experiments carried out with duplicates. 
At high tryptophan concentrations, root growth was even higher in the presence of $S$. scabiei than in the absence of the pathogenic agent. Because tryptophan reduced plant growth, one could suppose that this effect on radish seedling growth was due to the utilization of tryptophan by the bacterium. This was not the case because, at the end of the experiment, tryptophan concentrations remained very similar in inoculated and noninoculated growth pouches. Other examples of typical plant-microbe interactions that are redefined under certain conditions have been reported. At high phosphorus concentrations, growth of plants associated with arbuscular mycorrhizal fungi is negatively impacted, in contrast with the reciprocal benefits to the symbionts typically described $(13,19,20,33)$.

The reduction of thaxtomin A production by $S$. scabiei in the presence of high tryptophan concentrations may explain the decrease of symptoms in its host under these particular conditions. The reduced biosynthesis occurred, at least in part, from a downregulation of txtA and nos gene transcription. Nevertheless, the reduction of thaxtomin $\mathrm{A}$ synthesis in the presence of high tryptophan concentration could not explain the beneficial effect of the presence of $S$. scabiei on the radish root system. This observation suggests that $S$. scabiei produces extracellular metabolites, such as IAA, that stimulate root development. The involvement of bacterial IAA seems highly probable, although this must be interpreted with caution due to the difficulty in distinguishing between IAA of different origins in the growth pouches. Nevertheless, the contribution of bacterial sources of IAA, even in small amounts, has been shown to modify root growth in other systems $(35,42)$. Furthermore, application of low amounts of tryptophan to soil improved the growth and yield of various plant species through conversion to IAA by soil microorganisms $(3,9,51)$. Thus, it could be expected that the combined effect of low amounts of tryptophan on thaxtomin A and IAA biosynthesis would be beneficial to plant development.

Foliar application of auxin-like substances such as 2,4-dichlorophenoxyacetic acid (2,4-D) or 3,5-dichlorophenoxyacetic acid can significantly reduce the severity and occurrence of common scab on potato tubers $(38,46)$. It has been shown that accumulation of $2,4-\mathrm{D}$ in tubers is associated with enhanced resistance to thaxtomin A (46). It was also suggested that this result was dose dependent and more efficient at high auxin concentrations. Therefore, a significantly increased amount of IAA in the rhizosphere, even at a very local scale, may induce similar disease resistance properties in radish seedlings.

Because exogenous application of tryptophan reduced plant growth and tuber yield at concentrations similar to those tested in this study (1), potato field amendment with high quantities of tryptophan, in an attempt to prevent thaxtomin A production by $S$. scabiei, would be impractical. However, the addition of small quantities of tryptophan might increase auxin production by $S$. scabiei and other rhizosphere-associated microorganisms (51), thereby contributing to plant growth promotion. Because thaxtomins are the main components in the arsenal of the plant pathogen S. scabiei (36), development of control methods that aim to eliminate or diminish the effects of these molecules may represent promising avenues $(7,28)$. Screening for tryptophan analogs that inhibit thaxtomin biosynthesis without having a toxic effect on plant growth could eventually lead to a successful solution to control common scab.

\section{ACKNOWLEDGMENTS}

This work was supported by grants from the Natural Sciences and Engineering Research Council of Canada (NSERC) and the Fonds québécois de la recherche sur la nature et les technologies (FQRNT). We thank A.-M. Simao-Beaunoir for a critical review of the manuscript.

\section{LITERATURE CITED}

1. Ahmad, M., Pervez, M. A., Tahir, F. M., and Anwar-Ul-Haq. 1999. Effect of L-tryptophan on the growth and yield of potato cv. Pars-70. Int. J. Agric. Biol. 1:30-32.

2. Babcock, M. J., Eckwall, E. C., and Schottel, J. L. 1993. Production and regulation of potato-scab-inducing phytotoxins by Streptomyces scabies. J. Gen. Microbiol. 139:1579-1586.

3. Barazani, O., and Friedman, J. 2000. Effect of exogenously applied Ltryptophan on allelochemical activity of plant-growth-promoting rhizobacteria (PGPR). J. Chem. Ecol. 26:343-349.

4. Bartel, B. 1997. Auxin biosynthesis. Annu. Rev. Plant Physiol. Plant Mol. Biol. 48:51-66.

5. Beauséjour, J., Goyer, C., Vachon, J., and Beaulieu, C. 1999. Production of thaxtomin A by Streptomyces scabies strains in plant extract containing media. Can. J. Microbiol. 45:764-768.

6. Costacurta, A., and Vanderleyden, J. 1995. Synthesis of phytohormones by plant-associated bacteria. Crit. Rev. Microbiol. 21:1-18.

7. Doumbou, C. L., Akimov, V., and Beaulieu, C. 1998. Selection and characterization of microorganisms utilizing thaxtomin A, a phytotoxin produced by Streptomyces scabies. Appl. Environ. Microbiol. 64:43134316.

8. Faucher, E., Savard, T., and Beaulieu, C. 1992. Characterization of actinomycetes isolated from common scab lesions on potato tubers. Can. J. Plant Pathol. 14:197-202.

9. Frankenberger, W. T., Jr., Chang, A. C., and Arshad, M. 1990. Response of Raphanus sativus to the auxin precursor, L-tryptophan applied to soil. Plant Soil 129:235-241.

10. Fry, B. A., and Loria, R. 2002. Thaxtomin A: Evidence for a plant cell wall target. Physiol. Mol. Plant Pathol. 60:1-8.

11. Goyer, C., and Beaulieu, C. 1997. Host range of streptomycete strains causing common scab. Plant Dis. 81:901-904.

12. Goyer, C., Vachon, J., and Beaulieu, C. 1998. Pathogenicity of Streptomyces scabies mutants altered in thaxtomin A production. Phytopathology 88:442-445.

13. Graham, J. H., and Eissenstat, D. M. 1998. Field evidence for the carbon cost of citrus mycorrhizas. New Phytol. 140:103-110.

14. Healy, F. G., Wach, M., Krasnoff, S. B., Gibson, D. M., and Loria, R. 2000. The txtAB genes of the plant pathogen Streptomyces acidiscabies encode a peptide synthetase required for phytotoxin thaxtomin A production and pathogenicity. Mol. Microbiol. 38:794-804.

15. Hill, J., and Lazarovits, G. 2005. A mail survey of growers to estimate potato common scab prevalence and economic loss in Canada. Can. J. Plant Pathol. 27:46-52.

16. Hsu, S.-Y. 2010. IAA production by Streptomyces scabies and its role in plant microbe interaction. Ms.D. thesis, Cornell University, Ithaca, NY.

17. Hutcheson, S. W., and Kosuge, T. 1985. Regulation of 3-indoleacetic acid production in Pseudomonas syringae pv. savastanoi. J. Biol. Chem. 260:6281-6287.

18. Idris, E. E., Iglesias, D. J., Talon, M., and Boriss, R. 2007. Tryptophandependent production of indole-3-acetic acid (IAA) affects level of plant growth promotion by Bacillus amyloliquefaciens FZB42. Mol. PlantMicrobe Interact. 20:619-626.

19. Johnson, N. C. 1998. Responses of Salsola kali and Panicum virgatum to mycorrhizal fungi, phosphorus and soil organic matter: Implications for reclamation. J. Appl. Ecol. 35:86-94.

20. Jones, M. D., and Smith, S. E. 2004. Exploring functional definitions of mycorrhizas: Are mycorrhizas always mutualisms? Can. J. Bot. 82:10891109.

21. Joshi, M. V., Bignell, D. R. D., Johnson, E. G., Sparks, J. P., Gibson, D. M., and Loria, R. 2007. The AraC/XylS regulator TxtR modulates thaxtomin biosynthesis and virulence in Streptomyces scabies. Mol. Microbiol. 66:633-642.

22. Kers, J. A., Wach, M. J., Krasnoff, S. B., Widom, J., Cameron, K. D., Bukhalid, R. A., Gibson, D. M., Crane, B. R., and Loria, R. 2004. Nitration of a peptide phytotoxin by a bacterial nitric oxide synthase. Nature 429:79-82.

23. King, R. R., and Lawrence, C. H. 2001. Herbicidal properties of the thaxtomin group of phytotoxins. J. Agric. Food Chem. 49:2298-2301.

24. King, R. R., Lawrence, C. H., and Calhoun, L. A. 1992. Chemistry of phytotoxins associated with Streptomyces scabies, the causal organism of potato common scab. J. Agric. Food Chem. 40:834-837.

25. King, R. R., Lawrence, C. H., and Clark, M. C. 1991. Correlation of phytotoxin production with pathogenicity of Streptomyces scabies isolates from scab infected potato tubers. Am. Potato J. Res. 68:675-680.

26. King, R. R., Lawrence, C. H., Clark, M. C., and Calhoun, L. A. 1989. Isolation and characterization of phytotoxins associated with Streptomyces scabies. J. Chem. Soc. Chem. Commun. 13:849-850.

27. Lauzier, A., Goyer, C., Ruest, L., Brzezinski, R., Crawford, D. L., and Beaulieu, C. 2002. Effect of amino acids on thaxtomin A biosynthesis by 
Streptomyces scabies. Can. J. Microbiol. 48:359-364.

28. Lazarovits, G., Hill, J., King, R. R., and Calhoun, L. A. 2003. Biotransformation of the Streptomyces scabies phytotoxin thaxtomin A by the fungus Aspergillus niger. Can. J. Microbiol. 50:121-126.

29. Leiner, R. H., Fry, B. A., Carling, D. E., and Loria, R. 1996. Provable involvement of thaxtomin A in pathogenicity of Streptomyces scabies on seedlings. Phytopathology 86:709-713.

30. Lerat, S., Babana, A. H., El Oirdi, M., El Hadrami, A., Daayf, F., Beaudoin, N., Bouarab, K., and Beaulieu, C. 2009. Streptomyces scabiei and its toxin thaxtomin A induce scopoletin biosynthesis in tobacco and Arabidopsis thaliana. Plant Cell Rep. 28:1895-1903.

31. Lerat, S., Simao-Beaunoir, A.-M., and Beaulieu, C. 2009. Genetic and physiological determinants of Streptomyces scabies pathogenicity. Mol. Plant Pathol. 10:579-585.

32. Lerat, S., Simao-Beaunoir, A.-M., Wu, R., Beaudoin, N., and Beaulieu, C. 2010. Involvement of the plant polymer suberin and the disaccharide cellobiose in triggering thaxtomin A biosynthesis, a phytotoxin produced by the pathogenic agent Streptomyces scabies. Phytopathology 100:91-96.

33. Li, H., Smith, F. A., Dickson, S., Holloway, R. E., and Smith, S. E. 2008. Plant growth depressions in arbuscular mycorrhizal symbioses: Not just caused by carbon drain? New Phytol. 178:852-862.

34. Locci, R. 1994. Actinomycetes as plant pathogens. Eur. J. Plant Pathol. 100:179-200.

35. Loper, J. E., and Schroth, M. N. 1986. Influence of bacterial sources of indole-3-acetic acid on root elongation of sugar beet. Phytopathology 76:386-389.

36. Loria, R., Bukhalid, R. A., Creath, R. A., Leiner, R. H., Olivier, M., and Steffens, J. C. 1995. Differential production of thaxtomins by pathogenic Streptomyces species in vitro. Phytopathology 85:537-541.

37. Manulis, S., Shafrir, H., Epstein, E., Lichter, A., and Barash, I. 1994. Biosynthesis of indole-3-acetic acid via the indole-3-acetamide pathway in Streptomyces spp. Microbiology 140:1045-1050.

38. McIntosh, A. H., Bateman, G. L., Chamberlain, K., Dawson, G. W., and Burrell, M. M. 1981. Decreased severity of potato common scab after foliar sprays of 3,5-dicholorophenoxyacetic acid, a possible antipathogenic agent. Ann. Appl. Biol. 99:275-281.

39. McIntosh, A. H., Chamberlain, K., and Dawson, G. W. 1985. Foliar sprays against potato scab: Compounds related to 3,5-dichlorophenoxyacetic acid. Crop Prot. 4:473-480.

40. Palm, C. J., Gaffney, T., and Kosuge, T. 1989. Cotranscription of genes encoding indoleacetic acid production in Pseudomonas syringae subsp. savastanoi. J. Bacteriol. 171:1002-1009.

41. Patten, C. L., and Glick, B. R. 1996. Bacterial biosynthesis of indole-3acetic acid. Can. J. Microbiol. 42:207-220.

42. Patten, C. L., and Glick, B. R. 2002. Role of Pseudomonas putida indoleacetic acid in development of the host plant root system. Appl. Environ. Microbiol. 68:3795-3801.

43. Pfaffl, M. W. 2001. A new mathematical model for relative quantification in real-time RT-PCR. Nucleic Acids Res. 29:2002-2007.

44. Romero, J., Liras, P., and Martín, J. F. 1986. Utilization of ornithine and arginine as specific precursors of clavulanic acid. Appl. Environ. Microbiol. 52:892-897.

45. Spaepen, S., Vanderleyden, J., and Remans, R. 2007. Indole-3-acetic acid in microbial and microorganism-plant signaling. FEMS Microbiol. Rev. 31:425-448.

46. Tegg, R. S., Gill, W. M., Thompson, H. K., Davies, N. W., Ross, J. J., and Wilson, C. R. 2008. Auxin-induced resistance to common scab disease of potato linked to inhibition of thaxtomin A toxicity. Plant Dis. 92:13211328.

47. Vega-Hernández, M. C., León-Barrios, M., and Pérez-Galdona, R. 2002. Indole-3-acetic acid production from indole-3-acetonitrile in Bradyrhizobium. Soil Biol. Biochem. 34:665-668.

48. Vilches, C., Méndez, C., Hardisson, C., and Salas, J. A. 1990. Biosynthesis of oleandomycin by Streptomyces antibioticus: Influence of nutritional conditions and development of resistance. J. Gen. Microbiol. 136:1447-1454.

49. Woodward, A. W., and Bartel, B. 2005. Auxin: regulation, action, and interaction. Ann. Bot. 95:707-735.

50. Xu, Z., and Cen, P. 1999. Stimulation of avermectin B1a biosynthesis in Streptomyces avermitilis by feeding glucose and propionate. Biotechnol. Lett. 21:91-95.

51. Zahir, Z. A., Ateeq-ur-Rahman, M., and Arshad, M. 2000. Improving crop yields by the application of an auxin precursor L-tryptophan. Pak. J. Biol. Sci. 3:133-135. 